\title{
TEMPORALIZACIÓN INTERSUBJETIVA Y TIEMPO DEL MUNDO en EL PENSAMIENTO DE EDMUnd HusSERL
}

María Dolores Illescas Nájera Facultad de Filosofía y Letras, UNAM/Universidad Iberoamericana mdin2856@prodigy.net.mx

\section{Resumen}

El presente artículo se propone explorar la cuestión sobre cómo se constituye el tiempo cósmico u objetivo sobre la base del tiempo subjetivamente vivido. Problemática que se trata particularmente en algunos manuscritos del Husserl de los años treinta. Se sugiere que el adecuado esclarecimiento de esta cuestión implica, necesariamente, la distinción entre una temporalización de carácter propiamente yoico y la temporalización intermonádica o intersubjetiva. Y también, por otro lado, el caer en la cuenta de que en ausencia de una cierta "naturalización" como ser en el mundo, la autoconstitución del ego trascendental en el tiempo (o como tiempo) no podría alcanzar una verdadera constitución del mundo.

Palabras clave: Husserl, fenomenología, tiempo, intersubjetividad, presente vivido. 


\section{Intersubjective Temporalization and Time of the World in Husserl's Phenomenology}

\section{Abstract}

The main concern of this paper is to explore the question of how objective or cosmic time is constituted on the basis of the lived subjective time, particularly in Husserl's late manuscripts (1929-34). This problematic implies necessarily, as some of the different steps involved in the process that lead up to the full objective time, on the one hand, the distinction between egoic and intermonadic temporalization. And, on the other hand, the realization that in the absence of a certain "naturalization" as human being in the world, the self-constitution of the transcendental ego in time could not reach a truly constitution of the world.

Keywords: Husserl, Phenomenology, Time, Intersubjectivity, Living present. 


\section{Introducción}

Es bien sabido que, en el pensamiento de Husserl, el tiempo inmanente (es decir, aquel que inhiere necesariamente en la vida de conciencia), se distingue del tiempo objetivo o cósmico precisamente porque "desde" él se constituye todo sentido que este último pudiera cobrar. Estos dos tiempos son distintos, no se confunden, y sin embargo señala el filósofo en repetidas ocasiones que "coinciden punto por punto", "encajan uno en otro" en íntima correspondencia e incluso se resuelven en uno, "son [a priori] un único orden de tiempo” (Husserl, 1997a: pp.224, 251). Por ello, si el tiempo es la forma última de la subjetividad, y por ende la forma que subtiende necesariamente al entretejimiento de las vidas fluyentes de todos los sujetos que constituyen (o dan sentido a) un mismo mundo objetivo, no por eso deja de ser también la forma propia de dicho mundo.

Podría decirse, entonces, que se dan "a la vez" o concuerdan tiempo inmanente y tiempo mundano porque para que haya sentido de mundo tiene que haber precisamente una intersubjetividad que opera en su tiempo intermonádico constituyente; mas este último, que es fundado, tiene como soporte o "base" la originaria temporalización del tiempo inmanente que acontece en cada sujeto singular. Con lo cual tenemos una suerte de temporalización de temporalizaciones monádicas, ${ }^{1}$ todas ellas ocurriendo "a la vez". Sin embargo, la constitución del sentido "otro yo" implica la constitución de mí mismo en tanto ser humano, es decir, conlleva la mundanización o "naturalización” de cada mónada y con ello la temporalización de la misma en la espacio-temporalidad del mundo, y esto no como algo meramente accidental, sino como indispensable en la propia constitución de cada yo monádico, con su propia vida y sus habitualidades, con su psiquismo ligado a su único cuerpo propio.

El análisis de la relación entre el tiempo intersubjetivo trascendental y el tiempo objetivo del mundo, sobre todo en algunos textos

1 Por "mónada" se entiende la vida de conciencia del ego tomado en su plena concreción, es decir, como aquel polo idéntico de todos sus actos y sustrato de sus habitualidades que, precisamente a través de la multiformidad de su vida intencional (con toda la variedad de objetos de distinta índole mentados en ella), se concreta y singulariza (cfr. Husserl, 1996: p. 122). 
de los años 30, nos permitirá descubrir el avance del filósofo moravo hacia el reconocimiento (que sin embargo él mismo no llegó a hacer), del hecho fundamental de la encarnación de la conciencia como lo que en última instancia soporta (e incluso puede llevar a superar) el paralelismo entre estas dos dimensiones temporales.

\section{Tiempo de la conciencia y tiempo del mundo}

La fenomenología nos ha enseñado que nada podemos saber de los distintos tipos de objetos u objetualidades (esto es, "estados de cosas", partes o aspectos concretos o abstractos de las cosas) sino en cuanto éstos aparecen, es decir, nos son, precisamente, dados. Mas lo anterior no puede separarse del hecho, verdaderamente crucial, de que el acontecer mismo de la conciencia se nos revela como un flujo incesante, de donde se desprende que todo aquello que, de uno u otro modo se nos muestra habrá de hacerlo necesariamente en una temporalización fluyente, inclusive la propia mirada de la reflexión. ${ }^{2}$

Ahora bien, nuestra experiencia del mundo nos lo entrega no como terminado de una vez y para siempre, a la manera de una formación inmóvil, sino en un constante proceso de temporalización. En efecto, todo lo cósico, todo aquello que para nosotros es real (espaciotemporal), lo es precisamente por cuanto dura o permanece siendo lo que es a través de su cambio o modificación constante, por muy lento que éste pudiera parecer. Sin duda, el mundo es y permanece, en y con todo su contenido de realidad, en una imparable

2 En referencia al ámbito de la percepción (que, no lo olvidemos, constituye la conciencia intuitiva por excelencia), Husserl afirma que antes de cualquier pregunta por la realidad objetiva está el hecho o, más que esto, la peculiaridad esencial de que todas las apariciones son "dadoras de tiempo" (y de un modo tal que todos los tiempos dados se integran en un tiempo único). $Y$ dado que todos los individuos percibidos y por percibir poseen la forma común del tiempo, se sigue que "ésta es la forma primera y fundamental, la forma de todas las formas, el supuesto de todas las demás conexiones que forman unidad". Es claro que aquí "forma" significa el carácter que antecede necesariamente a todo lo demás, como la posibilidad misma de acceder a una unidad intuitiva. La temporalidad como duración, como simultaneidad o como sucesión es, pues, la forma necesaria de todos los objetos que se dan unitariamente en la intuición (Husserl, 1980: p. 180). 
fluencia. Pero si bien es cierto que el mundo puede decirse en sí mismo temporal, de manera que a su propio presente concreto pertenecen su pasado y futuro mundanos, también lo es que lleva en esto una insoslayable relación con el sujeto. Tenemos dado, pues, un mundo objetivamente temporal en nuestra subjetiva y viviente temporalización, en los fluyentes modos de aparición de todo lo que se nos presenta como actual, pasado o futuro. El cómo de tal modo de ser temporal (objetivo) se muestra en los correspondientes modos fenoménicos a través de los cuales (y sólo a través de los cuales) el mundo exhibe su temporalidad propia.

En otras palabras, el presente del mundo es conocido en el más amplio sentido en relación intencional con mi presente y mi experiencia, aunque también a través de mis pensamientos, recuerdos, etc., se muestra y puede ser caracterizado como mundo pasado $-\mathrm{O}$ futuro- en tanto corresponde a mi propio pasado y futuro que pertenecen, a su vez, a mi propio presente vivo, dado que sin él nada serían. Pero lo más importante aquí es que como yo "despierto" (o activo) tengo en el presente viviente, "en” el cual soy y opero, mi campo de mundo "presente", o, dicho de otro modo: mi mundo consciente lo es originalmente como mundo temporalmente presente.

La modalidad temporal que corresponde al presente del mundo se constituye, como sabemos, a través de la percepción. Percepción, naturalmente, de una esfera impresional de objetos que son directamente presentes pero también, aunque en forma modificada, del entero campo perceptivo que los circunda como todo aquello que, visible o no, les resulta "simultáneo". En efecto, todo lo mundano es "a la vez" ahora. Y lo que es "simultáneo" se mantiene en una forma espacial universal, pero ésta a su vez se encuentra soportada por una forma temporal universal, de la misma manera que la duración individual envuelve cada objeto singular como forma de todas sus determinaciones, y ello ocurre de un modo tal que todo lo que es la cosa física, lo es precisamente como unidad de su duración. ${ }^{3}$ Así,

3 Hay que advertir aquí, pues, que todo aquello que se da simultáneamente ocupa los mismos "lugares" o momentos en el tiempo, con la misma unicidad. En cuanto a la extensión espacial (o "figura corporal"), ella podría considerarse también como un contenido de la duración propia del objeto de que se trate, esto es, lo que la va "ocu- 
el tiempo del mundo se revela como la forma invariable para todo lo que existe, es decir, persiste o dura en el sentido de lo real (Husserl, 2006: p. 404). Pero además, por esto mismo, sucede que todos los individuos concretos que se dan a la conciencia en intuiciones (aunque inconexas en una primera aproximación), pertenecen a la unidad de un mismo tiempo que, si bien no es intuitivo, puede sin embargo llegar a serlo gracias a la actualización de las intenciones que se encuentran implicadas en los actos intuitivos y que pueden ser llevadas a dación. Pues toda percepción tiene sus horizontes que pueden desenvolverse en una infinidad de intuiciones posibles, a las cuales corresponden objetividades que, gracias a ese desplegarse, se hacen conscientes como dadas todas ellas en un mismo tiempo objetivo (Husserl, 1980: pp.180-181).

En la corriente de las modalidades temporales subjetivas se constituye, entonces, el unitario tiempo del mundo tanto como el mismo mundo en cuanto estable y permanente, puesto que en todos los trayectos y fases temporales (también en los presentes ya pasados y futuros) se reitera como absolutamente uno e idéntico a través de su incesante cambio, con lo cual se pone también de manifiesto la forma espacio-temporal fija que le pertenece de manera esencial.

pando" o llenando sucesivamente, fase por fase, mientras tiene lugar precisamente su desarrollo temporal. Pero esto significa que cada instante de esta duración es ya por su contenido algo espacial. Ahora bien, cada punto espacial es absolutamente único en el tiempo como aquello que "Ilena" espacialmente la forma temporal. Por eso es que numerosas cosas enteramente semejantes pueden presentarse en el espacio de manera simultánea; lo que las individualiza es su respectivo lugar en el espacio que hace de una y otra figuras corporales algo único en el tiempo. Cada punto del espacio, cada tramo de espacio, no puede ser real más que una sola vez, no puede estar ocupado por partida doble. En todo esto es claro que el tiempo es una forma superior en relación con el espacio, ya que este último es constituido como forma constante del contenido temporal, es decir, como perteneciendo a un contenido que dura. La unicidad de cada punto espacial es entonces unicidad en el seno de cada fase posible de la duración. Y así, aunque el espacio es la forma que individualiza lo coexistente, lo es por cuanto supone ya al tiempo, puesto que todo lo que es la cosa corporal lo es precisamente como unidad de su duración. (Véase al respecto Husserl, 1998: pp. 92-93). 
La percepción y sus capas pasivas

Sin duda, la orientación perceptiva hacia objetos particulares y su aprehensión efectiva constituye una labor activa del yo. Pero ésta supone que algo está pre-dado al sujeto percipiente, algo hacia lo cual éste puede dirigirse precisamente en el modo propio de tal conciencia perceptiva. Mas para que esto ocurra, tuvo que haber antes una determinada afección sobre el yo que nunca proviene de un objeto individual aislado, sino que comporta un cierto destacarse de dicho objeto contra el trasfondo de un determinado contexto o campo que siempre coexiste con él, de manera que gracias a este destacarse puede atraer sobre sí, "estimular", el interés perceptivo del yo (Husserl, 1980: p. 78). Dicho contexto contra el cual se destaca lo que afecta, puede considerarse, entonces, como el ámbito "de lo predado pasivamente". ${ }^{4}$ Más aún, podría decirse que en cierto modo toda percepción externa se "funda" en (o supone) la constitución de un contenido inmanente, ya que, de acuerdo con el pensamiento husserliano, los objetos trascendentes se constituyen en ella precisamente por medio de la apercepción de complejos de datos sensibles que, justo al ser apercibidos o "interpretados" intencionalmente, "exhiben" determinados aspectos de la cosa percibida.

Así pues, para que un objeto trascendente pueda darse originariamente, la vivencia perceptiva en cuestión debe contar con una determinada estructura, es decir, debe ser fluyente y hallarse en ella una corriente inmanente de fases vivenciales, de datos hiléticos (o sensibles) y sus respectivas aprehensiones, transcurriendo todo ello en el tiempo fenomenológico. Toda percepción externa ha de darse, por tanto, necesariamente en conformidad con un cierto transcurso continuo de captación "interna" (o constitución originaria) de temporalidades inmanentes, de modo que a través de este curso "perceptivo" inmanente se despliega una doble intencionalidad, en la que el objeto externo en su trascendencia, así como su tiempo objetivo, viene a dación originaria a través justamente de su aparición, que es, asimismo, fluyente (Husserl, 2001: p. 165).

4 Es decir, "de un estar previo que siempre está ahí sin que se le agregue nada, sin que se le dirija la mirada captadora, sin que despierte el interés" (Husserl, 1980: pp.30-31). 
En dicha captación inmanente (que ha de ser entendida ante todo en términos de sensación) se presenta un continuo de datos sensibles, ya sean iguales o continuamente cambiantes, que cumplen (erfüllen) o "realizan" un trayecto del tiempo inmanente, con lo cual son dados como originariamente "percibidos". Y sobre ésta, su constitución más básica, más elemental, que no es otra cosa sino la formación misma del tiempo propio de la vida de conciencia, tienen lugar una serie de asociaciones pasivas (que ocurren por semejanza o por contraste) y que, al permitir la integración y ordenación de la multiplicidad de datos hiléticos en los diversos campos sensibles (ya sea como simultáneos o sucesivos), brindan el contenido sensible indispensable para que un acto perceptivo pueda efectuarse. ${ }^{5}$

Es en este contexto donde debe ubicarse la primera y originaria temporalización del presente como modalidad temporal, esto es, su temporalización como presente impresional concreto en la esfera hilética, de donde vendrá luego la formación de las modalidades temporales del pasado y del advenir. Pero también debido a ello, reconoce Husserl con toda claridad, el concepto de presente estricto que lo plantea como una suerte de impresión instantánea, no puede referirse en realidad sino a una mera abstracción. Frente a dicha abstracción tenemos otro concepto de presente más concreto, perteneciente ahora al objeto concreto constituido, que está necesariamente en una corriente y se conforma como presente precisamente en tanto y mientras dura. En este sentido, lo impresional en la percepción ha de ser referido no ya al mero momento presente como tal, sino a algo idéntico que dura y en ello se mantiene como lo mismo, permaneciendo como existente en el continuo proceso de su devenir. Las continuas impresiones noético-noemáticas son así, ante todo, constitución de una unidad concreta duradera (Husserl, 2006: pp.83-84). Por lo que puede afirmarse que incluso el cambio de una impresión originaria o protoimpresión (Urimpression) a la siguiente,

5 Puede afirmarse, entonces, en términos muy generales, que lo impresional es una unidad (de fusión) de lo impresional simultáneo y tiene su forma fija idéntica, en la que puede distinguirse un doble aspecto: la forma de campo específica para cada campo hilético (sensible) y lo esencialmente cualitativo (p. ej. determinados contenidos visuales) que lo concretan. 
exhibe ya una suerte de concordancia en tanto cumplimiento de una protención o preanticipación (motivada esta última, al menos en algún grado, por lo que ya ha sido experimentado).

Con todo, si atendemos ahora precisamente a la conciencia última donde tiene lugar la mismísima formación de la inmanencia, encontraremos que toda temporalización posible acontece sólo en la vivacidad; es "en" o "desde" el presente viviente "donde" operan originariamente, son y cobran sentido para mí aún el pasado y el futuro lejanos. En el presente viviente se efectúa la temporalización de todos los tiempos, así como también se opera, en todos sus niveles, la constitución del mundo. Pues de lo que aquí se trata es nada menos que del origen (Ursprung) radical de todo sentido y toda experiencia en un protofluir que puede decirse no ya sólo "preobjetivo" sino incluso "preintencional” en el sentido de que antecede (y funda) la intencionalidad en el sentido estricto (que es propia de los actos propiamente dichos).

El proceso originario de temporalización como la emergencia misma de la subjetividad y a la vez de un pre-mundo

Es bien sabido que en las Lecciones de fenomenología de la conciencia interna del tiempo Husserl caracterizó a la conciencia última constituyente de tiempo como la subjetividad absoluta. Y que en sus manuscritos de los años treinta en torno a la cuestión del tiempo, señaló de nueva cuenta como tal instancia última al presente primigenio (die urtümliche Gegenwart), sólo que ahora entendido en términos de la autotemporalización trascendental del ego en dicho pre-presente permanente y primigenio (stehend-urtümliche Vor-Gegenwart). ${ }^{6}$ En efecto, para estos años Husserl ya había reconocido sin titubeos el carácter propiamente yoico de la corriente conciencial autoconstituyente e

6 Pre-presente porque "desde" él se presentan, por así decirlo así, los "ahoras" que, como momentos temporales propiamente dichos, pasan y se van hundiendo gradualmente en el pasado, y también porque no se trata ya de ninguna modalidad propiamente temporal, puesto que se trata de la instancia formadora de todas ellas (véase al respecto Walton, 1984: pp.44ss.). 
incluso llega a afirmar que tal yo sólo es concreto a través del contenido del presente fluyente que se forma pasivamente, desplegándose en la forma de un acontecer que subyace a toda actividad de conciencia (Husserl, 2006: p.53).

Pero justamente a propósito del tema de la conciencia última y las fases peculiares que la conforman, un punto crucial se había adelantado ya desde los años tempranos de 1910-11. En efecto, según lo planteado en las Lecciones..., la protoimpresión o conciencia estricta del ahora en el seno del campo originario de presencia constituye el germen mismo que desencadena la formación del proceso de temporalización propio del flujo conciencial bajo la consabidas series retencionales (que conservan la conciencia de lo que "justamente acaba de pasar”) y también protencionales (en estas últimas tendríamos una especie de "puesta en espera" del todo inmediata). Ahora bien, en dicho núcleo se da una especie de identificación total de conciencia con no-conciencia, una extraña fusión de lo que no es de suyo producción de la conciencia (a saber, el dato hilético) y la emergencia misma de la propia conciencia en cuanto conciencia inmodificada u originaria por excelencia (dado que tanto retención como protención pueden ser ya consideradas como series graduadas de modificaciones concienciales). La constante emergencia de la actualidad se manifiesta a la conciencia, entonces, precisamente por cuanto, a cada instante, ella se encuentra afectada por una impresión. Pero hay más, puesto que, según afirma Husserl, la propia conciencia no es nada sin la impresión. ${ }^{7}$ De manera

7 La impresión originaria (o protoimpresión) es caracterizada, en efecto, en las Lecciones... como el comienzo absoluto de esta producción conciencial, la fuente originaria de la que todo lo demás se produce sin cesar. "Ella misma, sin embargo, no se produce, no surge como algo producido, sino que lo hace por genesis spontanea, es engendramiento originario. No crece - no tiene germen-, es creación originaria. Tanto si decimos que un nuevo ahora se forma de continuo sobre el ahora que se modifica en no ahora, como si decimos que una fuente se produce o brota originariamente de súbito, todo ello son imágenes. Y únicamente cabe decir: la conciencia es nada sin impresión". Así, "donde algo - a- dura, a pasa a xa', xa' a yx'a", y así sucesivamente. La producción de la conciencia pasa, empero, de a a a', de xa' a x'a"; pero los $a, x, y$, no son, por el contrario, nada producido por la conciencia, sino lo originalmente engendrado, lo 'nuevo', lo que ha venido a ser, ajeno a la conciencia; lo recibido frente a la propia espontaneidad de la conciencia. La peculiaridad de esta espontaneidad de la conciencia es, con todo, que ella se limita a hacer crecer, a desplegar lo engendrado en origen, sin gestar nada 'nuevo'"' (Husserl, 2002: p. 120). 
que ni existe protoimpresión sin contenido hilético, ni hay ningún punto del tiempo inmanente sin este primer contenido, así como tampoco puede haber ningún trecho temporal hiléticamente vacío (Husserl, 2001: p. 282).

Lo anterior apunta sin duda al reconocimiento de un elemento de facticidad y de alteridad en la raíz más profunda de la vida del sujeto, elemento que, como lo extraño, lo "otro" de éste, le es pasivamente pre-dado e incluso lo afecta, pero es a la vez inseparable de él. Es claro que dicho elemento no puede entenderse simplemente como un mero "objeto trascendente", ya que el dato hilético no puede decirse todavía objeto y permanece en cambio como algo inmanente. ${ }^{8}$ Con todo, se mantiene en pie que la extrañeza que conlleva la hyle en el estrato más profundo de la vida de conciencia (y, es importante subrayarlo, previo a la distinción sujeto-objeto) pueda dar lugar más tarde, a la ulterior constitución del mundo, su necesario correlato. De ahí que este momento de autorreferencia que es la protoimpresión sea a la vez, indisociablemente, el surgimiento de lo que por su parte habrá de conformar un, por así decirlo, germen o núcleo ínfimo del mundo (Montavont, A., 1999: p.182). Por ello, al solo reconocimiento de que "la protosensibilidad, la sensación, etc., no nace a partir de bases inmanentes, de tendencias anímicas; [sino que] ella está simplemente ahí, se presenta" (Husserl, 1997a: p. 387) deberá seguir, años más tarde, el franco planteamiento de la llamada hyle primordial (esto es, los diversos campos sensibles, las sinestesias, afectos e instintos primordiales, todo ello sobre la formación del tiempo inmanente), como el ABC o "la gramática esencial del mundo", por cuanto dicho material primordial transcurre precisamente en una forma de unidad que hace posible, prefigurándola, la percepción de las cosas del mundo y de éste mismo como el horizonte general en el que aquéllas se sitúan. ${ }^{9}$

8 En el texto arriba citado, Husserl habla incluso de una especie de "entorno" hilético que pertenece a la forma esencial de la inmanencia, que rodea al ego y lo afecta, pero que de suyo no es de índole yoica. (Véase también a este respecto Zahavi, 1998: pp.205-228).

9 "[...] la indagación retrospectiva depara finalmente la estructura primordial, con su variación de hyle primordial, etc., con las cinestesias primordiales, afectos primordiales, instintos primordiales. Según esto en el propio factum yace el que este material pri- 
El tiempo es la forma misma de la subjetividad, pero a la vez el tiempo (objetivo) es la forma de todo lo real, la forma esencial del mundo. Y que ambos se prefiguren ya de algún modo en el meollo mismo del proceso temporalizador que acontece en el campo originario de presencia (más tarde el "presente viviente"), habrá de llevar al reconocimiento de la indisociabilidad del tiempo de la conciencia y del tiempo del mundo, aunque sepamos a la vez que no son lo mismo ni uno un simple elemento integrante del otro. Así, y por cuanto lo propiamente yoico se temporaliza en la temporalización protoasociativa a una e inseparablemente de lo hilético más elemental (Husserl, 2006: p. 53), se dará cauce al reconocimiento del ulterior surgimiento "a la vez" del mundo y del yo, por lo menos del mundo tal y como se muestra en la esfera primordial de este último (y en ese sentido sin cobrar todavía el estatuto verdadero del mundo objetivo, que lo es para todos los sujetos).

De aquí que, para estudiar la constitución de las modalidades temporales de lo mundano, el filósofo moravo nos invite a retroceder en un primer momento metódico a su constitución en la inmanencia (merced al atento examen del "cómo" de su respectivo aparecer) hasta desembocar en la prototemporalización de la subjetividad trascendental (dadora de sentido) y en ella a mi reducida temporalización egológica (singular), para luego abordar la coexistencia intersubjetiva de los sujetos y sus inmanencias y primordialidades, que en su entretejimiento fluyente dan lugar a una constitución intersubjetiva del mundo propiamente dicho, del mundo plenamente objetivo.

mordial discurra precisamente en una forma de unidad que es la forma de esencia de la mundanidad. Con ello parece que la constitución del mundo entero está prefigurada ya de modo 'instintivo' para mí, de suerte que las funciones que la hacen posible poseen de antemano el $A B C$ de su esencia, la gramática esencial del mundo. En el mismo factum yace, pues, que tenga lugar una teleología" (Husserl, 1973: p. 385. Texto traducido por Serrano de Haro, 1997: pp.5-14). 
El mundo objetivo y su tiempo como índice que apunta a la intersubjetividad

Ciertamente, el mundo que para mí existe se halla referido a mi vida de conciencia como manifestado en ella. Pero en esta misma vida experimento una temporalización inmanente y tengo en ella, en primer lugar, el presente de la propia vida, el presente de mi real humanidad en el mundo ahí. Mas yo solo puedo constituirme como un ser humano en medio de otros hombres de manera que no puedo decirme propiamente "yo" si no es en medio de un nosotros. ${ }^{10}$

El respectivo presente del mundo existente se sitúa, se temporaliza, para mí "en” o "desde” mi propio presente monádico (como ocurre a la vez para cada uno). De manera que dicho presente mundano queda ubicado originalmente en la forma de un presente que pertenece directamente a mi subjetividad concreta. Así, yo, que me encuentro a mí misma como ser humano, encuentro al mundo y también tengo recuerdos humanos de él, a través de los cuales puedo percatarme incluso del pasado propio del mundo. Sin embargo, al tomar en cuenta mi entero campo de experiencia, encuentro que este horizonte en su potencialidad remite indefectiblemente al copresente de los otros hombres, a la posibilidad de lo actualmente

10 Así pues, "A la aprehensión del hombre (en el sentido espiritual) en referencia a mí mismo, llego mediante la comprehensión de los otros, a saber, en la medida en que no solamente los comprendo como miembros centrales para el mundo circundante restante, sino también para mi cuerpo, que para ellos es objeto circunmundano. Precisamente por ello los comprehendo como aprehendiéndome a mí mismo de modo similar a como yo los aprehendo; aprehendiéndome, pues, como hombre social, como unidad comprehensiva de cuerpo y espíritu. Ahí yace una identificación entre el yo que encuentro en la inspección directa (como yo, que tengo enfrente mi cuerpo), y el yo de la representación ajena de mí, el yo que el otro, en actos que yo por mi parte le asigno al otro, puede comprender y poner a una con mi cuerpo como el representativamente "externo" a él. La representación comprehensiva que otros tienen o pueden tener de mí me sirve para aprehenderme a mí mismo como "hombre" social, o sea, aprehenderme de manera enteramente distinta que en la inspección directamente captante. Mediante esta especie de aprehensión complicadamente construida me dispongo en el conglomerado de la humanidad, o forjo más bien la posibilidad de constitutiva para la unidad de este "conglomerado". Ahora por vez primera soy propiamente yo frente al otro y puedo ahora decir "nosotros"; y ahora también llego por primerísima vez a ser "yo" y el otro precisamente otro; "nosotros" somos hombres, de la misma especie unos y otros, capacitados como hombres para entrar en trato unos con otros y contraer enlaces humanos" (Husserl, 1997: pp. 289-90; el subrayado es mío). 
comunitario. Más aún, cada presente del mundo es experimentado idénticamente por todo sujeto en medio del "nosotros", o, por decirlo de otro modo, transparece en el ser presentes unos-para-otros.

De manera que si el mundo siempre se me presenta como existiendo a través de su propio transcurso temporal, el cual se constituye para mí (la -o el-que experimenta) como una constante unidad o, mejor, como la forma misma del mundo (puesto que éste es dado necesariamente bajo tal forma), y como esta donación a mi propio ser apunta necesariamente a un "nosotros", bien podría abstraer de dicho modo de darse (aunque fuera solamente en sus rasgos más fundamentales), cómo los que son otros para mí y co-presentes conmigo, efectúan también la experiencia del mundo. El mundo cobra entonces, para mí, el sentido de un mundo accesible para todos -y con ello su propio tiempo-(Husserl, 2006: pp.415-416).

Lo anterior supone también, por otra parte, que la constitución de cada mónada exige su naturalización, pues al constituirse cada yo monádico inmediata y necesariamente en tanto yo psíquico y concreto, con su propia vida singular y sus habitualidades, va con ello el ser psique del único cuerpo propio de esta psique y con ello la temporalización de la misma en la espacio-temporalidad del mundo. Con lo cual el tiempo inmanente toma, en cierto modo, el sentido de un proceso en dicho tiempo objetivo o cósmico (Husserl, 1973: p.639). ${ }^{11}$

El tiempo del otro y el mío propio: el ahora como enlace original de las subjetividades

Recordemos ahora brevemente cómo se constituye el sentido de "otro yo". Encuentro el cuerpo vivo del otro como propiamente percibido y perceptible, aunque su vida de conciencia, como la mía para él, permanece tan sólo re-presentada (ya que, precisamente por

11 Con todo, lo anterior no debe hacernos perder de vista que, a fin de cuentas, el tiempo mundano sólo tiene sentido como existente (es decir, como presente), en relación al presenciar actual de los sujetos, mismos que son precisamente presente originariamente fluyente, en el ser-con-otro asimismo originariamente fluyente y que, en tanto comunidad, constitutivamente tienen el mundo. 
tratarse de "otro", no puedo acceder a ella inmediata, originariamente). Y, sin embargo, en el ser ahí uno para el otro, nos hallamos mutuamente como co-presentes. El cuerpo propio de todo otro es, pues, para todos los demás sujetos, cuerpo externo ahí (Körper), pero a la vez es vivido por él (como a mi vez yo vivo el mío) de una manera única, en su propia movilidad corporal. Así, el cuerpo del otro, en la relación de semejanza con el mío (experimentado en mi primordialidad), llega a ser captado en la empatía como portador de la apercepción del otro: de otro presente primigenio en el cual él constituye como cuerpo vivo (Leib) su propio cuerpo. Es decir, las constituciones de ambos cuerpos son rigurosamente correlativas y, por ende, las respectivas primordialidades coinciden sintéticamente, lo mismo que el tiempo de uno y otro (Husserl, 1973: p.331).

Pero además, el cuerpo (Leib) ajeno indica una totalidad de percepciones como las mías propias y en las cuales lo mismo existe para ambos. Mi percepción objetiva está en conexión con la suya, mi recuerdo objetivo se conecta con el suyo, asimismo se conectan mi mundo de experiencia real y posible y el suyo, tanto noética como noemáticamente, de manera que podemos llegar a reconstruir del mismo modo la esfera de lo percibido en común. ${ }^{12}$ Entonces, en la coincidencia constitutiva de la naturaleza espaciotemporal que se

12 Efectivamente, en mi presente actual puedo ser motivado no sólo por mis propias experiencias pasadas, sino también por el sentido propuesto por el otro que me es presente desde su propio pasado, es decir, en tanto historia viviente de sus habitualidades, sus creencias o convicciones; ellas pertenecen a ese otro en cuya temporalidad se entrecruzan también otras temporalidades contemporáneas y pretéritas que de una u otra manera perviven en la cultura. La configuración del mundo se da, así, desde las experiencias vividas intersubjetivamente. En ellas (como "intersubjetividad trascendental") se constituye un tiempo objetivo, común, dentro del cual ha de poder ordenarse todo lo individual, en lo que respecta tanto a vivencias como a objetividades intencionales. De manera que: "todas las percepciones y experiencias de un yo se encuentran en conexión respecto de sus objetos intencionales, se relacionan con un tiempo [...] Y asimismo: todas las percepciones y experiencias de todos los sujetos personales, que se entienden entre sí, se encuentran en conexión respecto de sus objetos intencionales —en la conexión de un tiempo objetivo, que se constituye en todos sus tiempos subjetivos, y de un mundo objetivo, que se constituye en ese tiempo". (Husserl, 1980: p.182). Lo cual significa que cada objetividad individual mundana tiene su realidad (en el sentido de identificabilidad objetiva) de un modo tal que se halla constituida intersubjetivamente en la unidad de un tiempo objetivo, el tiempo universal. En él todo objeto real tiene su sitio temporal fijo, que lo distingue individualmente de cualquier otro. 
presenta como la misma a cada yo primordial, cada yo que aparece como hombre psicofísico es el cuerpo vivido como propio de un sujeto que, sin embargo, se "localiza" o inserta mediante ese mismo cuerpo en la naturaleza -y con ello todo lo subjetivo suyo (Husserl, 1973: pp.581-582).

En todo ello aparece el "ahora" como el originario punto de enlace entre las subjetividades: yo capto al otro como siendo justamente "ahora", lo mismo que me capto a mí mismo como existiendo ahora. En mi presente viviente efectúo un acto de empatía ${ }^{13} \mathrm{y}$ al hacerlo tengo, a todo lo largo de la "extensión" temporal que alcanza la duración de este acto, mi propio presente y, en estrecha coincidencia con él, el presente del otro; sólo que este último no conforme a percepción, sino re-presentado. De manera que, por decirlo así, nuestros respectivos tiempos fluyen al unísono.

Por otra parte, yo no puedo tener experiencia del otro más que en tanto lo experimento justo como aquel que, a su vez, me experimenta a mí: el ego que se me presenta como alter es tal porque a la vez yo soy alter para él. Y dado que lo anterior conlleva la mundanización de ambos, el otro y yo, en tanto encarnados y co-partícipes del mundo humano y natural, así como su cuerpo físico-vivo se encuentra en mi campo perceptivo, así también el mío se halla en el suyo, etc.

Si desde este punto retrocedemos al ámbito propiamente trascendental, encontraremos que, en última instancia yo soy como presente viviente, y que mi ser para mí mismo es constituido en este mismo presente viviente-fluyente. Pero también los otros lo son para ellos mismos, aunque su ser para sí lo es igualmente para mí, en la forma de mi potencialidad de apresentación (Appräsentation). ${ }^{14} \mathrm{De}$ tal suerte, el otro es apresentado en mí y yo en él (Husserl, 2006:

13 Por empatía se entiende, en general, la experiencia gracias a la cual el yo que la tiene, tiene a la vez experiencia de la conciencia de otro yo (Husserl, 1994: p.122).

14 Por "apresentación" (o apercepción analógica) se entiende una especie de experiencia (re-presentativa) que da lo que del otro es inaccesible en originariedad (su vida de conciencia) aunque necesariamente entretejida con una presentación originaria (la percepción de "su" cuerpo físico en cuanto fragmento de la naturaleza). Véase al respecto, Husserl, 1996: p.177. 
p.56). Así pues, yo llevo a todos los otros en mí (como apresentados) y me apresento a la vez e inseparablemente como siendo llevado en ellos, así como llevo en mí mi ser pasado (y todos mis pasados) en mi presente. Mi vida "persistente y fluyente" es, por tanto, protomónada en la cual se implica ya el todo de las mónadas. ${ }^{15}$ Con otras palabras, en el presente viviente es todo otro ego trascendental constituido en mí como presente viviente y fluyente, como subjetividad fluyente copresente. Pero ello ocurre de tal modo, que precisamente coincidimos en el copresente apresentado que es el mismo co-punto fuente de los pasados mío, suyo y nuestros. Yo, como siendo presente concreto, viviente y fluyente, tengo en mí su presente en tanto co-presente re-presentado; pero también él, como yo mismo, me tiene constituido en su presente viviente en el modo del copresente (Husserl, 2006: p. 56). Los otros sujetos-yo existentes con sus mundos primordiales aparecen entonces como mis covalentes, y con ello la conciencia para mí del "mundo" extraño, consciente justamente como extraño-primordial. Con lo cual se efectúa un complejo proceso de síntesis de nuestras respectivas primordialidades (o esferas de experiencia propia, directamente vivida).

Por otro lado, conviene recordar que si bien en la vivacidad protofluyente (el presente viviente) tengo yo re-presentados la inmanencia del otro, y con ello su mundo y tiempo en capas y modos diversos, también desde aquí se abre un horizonte verdaderamente comunitario por cuanto soy también otro para los otros del otro con quien empatizo, de manera que con ello se da lugar a una serie abierta de empatías directas e indirectas, hasta alcanzar incluso grados muy elevados de iteración.

El ser de los otros es, entonces, justo como ser de otros presentes vivientes, "ubicado" desde mi presente. Ser-con-los-otros es

15 Ciertamente cada yo tiene implícito en sí su propio ser como ego frente a los alteri, pero ello se da sólo en la medida en que también tiene implícito el ser (según empatía) de todos los demás yo como modificaciones intencionales del propio -de modo análogo a como los yo pasados son modificaciones intencionales del propio yo presente. Mi yo primigenio implica, así, una infinitud del egos, cada uno de los cuales implica a su vez a todo otro a partir de sí mismo y, desde luego, entre ellos también a mi propio ego en el que, por cierto, todo eso está implícito, como precisamente ocurre otra vez en cada uno (puesto que somos alteri unos para otros). 
indisociable de mi ser-para-mí en mi mismo presente viviente.Y este copresente de los otros es fundante para el presente mundano, presupuesto para el sentido que pueda cobrar toda temporalidad del mundo con su coexistencia mundana (espacio) y su serie temporal (Husserl, 2006: p.57). Soy siempre en referencia a los otros, de manera que mi "haber" constituido bajo el título de mundo ${ }^{16}$, es el mismo haber de la intersubjetividad fluyente; es decir, el mundo es "haber" en la intersubjetividad originaria. Pero entonces a cada una de las mónadas en comunidad pertenece en su vida misma -y por tanto en su temporalidad trascendental, en el tiempo único de cada corriente conciencial singular-, siempre uno y el mismo mundo, con el mismo tiempo objetivo constituido.

Como ya se ha advertido, el yo sólo es en el "nosotros" y éste último necesariamente llega a ser tal en una comunidad abierta de

16 En el §33 de la cuarta de las Meditaciones Cartesianas Husserl afirma lo siguiente: "En cuanto ego, yo tengo un mundo circundante, 'existente para mí' perpetuamente, y en él objetos como 'existentes para mí, a saber, ya como conocidos para mí con una organización permanente, ya sólo anticipados como cognoscibles. Los primeros, los existentes para mí en el primer sentido, son de adquisición primitiva, de la explicitación de lo al pronto nunca divisado en intuiciones particulares. De esta manera se constituye en mi actividad sintética el objeto en la forma de sentido explícito: 'lo idéntico de sus variadas propiedades'; o sea, el objeto como idéntico consigo mismo, como lo que se determina en sus variadas propiedades. Esta actividad mía de poner el ser y hacer su exhibición funda una habitualidad de mi yo por virtud de la cual este objeto [...] es duradera propiedad mía. Estas adquisiciones duraderas constituyen mi respectivo y conocido mundo circundante, con su horizonte de objetos desconocidos, esto es, todavía por adquirir, anticipados con esta estructura objetiva formal" (1996: p.122). Se comprende entonces en qué sentido puede decirse que el mundo es mi "haber"; esto es, en tanto correlato (noemático) de la serie de habitualidades o disposiciones estables de un yo que éste ha ido ganando progresivamente (conforme va viviendo) y que, por decirlo así, se han "depositado" en él, haciéndolo cada vez más capaz de vivir experiencias nuevas y crecientemente complejas. Un poco más adelante (en el §38 de la misma Meditación), el autor afirma que gracias a la génesis pasiva (aunque también a la activa) de las variadas apercepciones que persisten en una habitualidad peculiar, el yo tiene incesantemente un contorno de "objetos", un horizonte predelineado de lo que puede experimentar. A la autoconservación de un yo que constituye su identidad unitaria y concreta a través de una multiplicidad de tomas de posición que permanecen (esto es, a sus habitualidades), ha de corresponder, entonces, la constitución de un mundo unitario, estable y duradero, un mundo objetivo que permanece conservado como el horizonte, siempre familiar, siempre "ya ahí", desde el cual aparece todo objeto que se percibe o puede percibirse. 
todas las personas ${ }^{17} \mathrm{y}$ teniendo como su correlato al mundo, que en tanto mundo empírico comunitario no se da sino como una unidad que se va troquelando y corrigiendo, aunque siempre de manera relativa, abierta a lo infinito. La problemática que con todo ello se plantea es crítica, pues atañe a la propuesta de un cierto paralelismo en lo tocante, por un lado, a la comunidad humana y, por otro, a la comunidad de sujetos trascendentales, siendo tomada la primera como una especie de índice que apunta indefectiblemente a la segunda (ya que no se trata sino de una autoobjetivación suya). ${ }^{18}$

Aunque desarrollada sobre todo en la década de los 30, dicha problemática había sido planteada por Husserl ya desde los años de 1910-11, en el curso titulado Problemas fundamentales de la fenomenología y con ocasión de la consideración del acto de empatía. Allí nos dice, en efecto, que el acto de empatía y el acto dado en ella pertenecen al mismo tiempo: "la empatía pone lo dado en empatía como ahora y lo pone en el mismo ahora en que se pone a sí misma" (Husserl, 1994: p. 125), con lo cual tenemos un ahora re-presentado (a saber, aquel que vive aquel con quien empatizo) y una identificación de tal ahora re-presentado con el ahora actual que, en cambio, sí es originalmente vivido. Pero lo más interesante en ello es que ese ahora que no está dado en sí mismo, que no es propiamente percibido, se re-presenta como "objetivo", como dado "a la vez" con un ahora que, en cambio, sí es dado por sí mismo, directamente. Es claro que, si se trata de la empatía empírica, el tiempo puesto en ella es sin mayor problema un ahora puesto empíricamente como el mismo punto temporal objetivo que es el ahora de la conciencia propia. Esta identificación estará mediada, entonces, por la referencia al tiempo

17 Conviene no olvidar en este punto que el yo personal es el yo que es consciente como sí mismo y en este sentido constituido para mí; se trataría, pues de una autoobjetivación en la que el yo se aprehende a sí mismo como parte de un mundo humano personal e interpersonal, por lo cual habrá que distinguirlo del yo descubierto al adoptar la actitud trascendental, pues este último es aquel que efectúa precisamente esta autoobjetivación.

18 Volveremos a encontrar el planteamiento de dicho paralelismo en El artículo de la Encyclopaedia Britannica (Husserl, 1990: pp.74-75) y también en La crisis de las ciencias europeas y la fenomenología transcendental (1991: pp.188ss). 
objetivo del cuerpo y del mundo espacial, cósico. Mas, se pregunta nuestro autor, ¿qué queda si ejercemos la reducción y desconectamos tanto la existencia de las cosas, junto con los cuerpos, como la existencia de la forma temporal del mundo cósico?

“Todo ser fenomenológico se reduce, entonces, a un (a 'mi') yo fenomenológico, que se distingue como el yo que percibe y recuerda, que tiene empatía (y, a la vez, practica la reducción fenomenológica), y también se reduce, por otra parte, a otros yoes puestos en la empatía, yoes puestos como viendo, recordando y eventualmente teniendo empatías" (Husserl, 1994: p.125). ${ }^{19} \mathrm{Y}$ como los yoes dados en empatía son puestos, gracias a la empatía natural, como pertenecientes a sus cuerpos, como centros de entornos cósicos que se extienden a la naturaleza total, habrá de resultar, por tanto,

[que] la naturaleza es índice para una regulación omnicomprensiva que abarca todas las corrientes de conciencia que por la empatía se refieren unas a otras en la relación de experiencia, especialmente cada punto objetivo del tiempo y cada 'simultáneamente' comprendido de modo objetivo, que pone unitariamente mi ahora presente y el ahora de otro yo [...] "Así cada punto objetivo del tiempo es índice para una coordinación [...] que, por decirlo así, lleva a relacionarse cada yo-mónada con todo otro (Husserl, 1994: p.126).

\section{Constitución del tiempo intermonádico}

Retomemos en este punto la comunidad de mónadas que, viviendo en un peculiarísimo "uno en otro" (Ineinander), se manifiestan como constituyentes de un mismo mundo objetivo a través de la re-presentación de los modos actuales y potenciales de la empatía.

19 Nótese que la reducción abraza así a la intersubjetividad que, como comunidad trascendental, da sentido al mundo. Algunos años más adelante -en el §54 de la CrisisHusserl corregirá esta postura, señalando que, desde el punto de vista metodológico, la intersubjetividad trascendental y su mancomunación trascendental sólo pueden mostrarse a partir del ego y de la sistemática de sus funciones y realizaciones trascendentales. 
Si consideramos tal uno-en-otro monádico actual como siendo en el mundo, encontraremos sin duda un cierto proceso de génesis monádica, un originarse y pasar de las mónadas, que nacen y mueren. A la duración de la vida del "alma" en el tiempo del mundo corresponde (parcialmente) la duración de la vida de otras mónadas. Se comprende que consideramos aquí al yo desde una perspectiva intermonádica, y por ende su duración de vida juntamente con la de las otras mónadas también en el tiempo del mundo, ya sea bajo el modo de la simultaneidad, total o parcial, ya bajo el de la sucesión, dado que la cohumanidad en cuyo marco experimento al mundo y a los otros como a mí mismo en tanto seres humanos, es también conexión generativa que se despliega al nivel de los contemporáneos, los antecesores y los sucesores.

Indudablemente, cada mónada existente tiene en sí misma y en comunidad con las para sí constituidas mónadas mundanas, su génesis "personal" como un yo monádico concreto y singular que desarrolla sus posibilidades, sus habitualidades, y que, en suma, va erigiendo en todo ello su ser propiamente personal. Cada mónada en su corriente de vida trascendental tiene, por tanto - en este sentido-, comienzo y fin, un trayecto de vida en el tiempo trascendental intermonádico (cfr. Husserl, 2006: pp.22, 369). Y sin embargo, a través de este constante cambio monádico se mantiene un general "uno en otro-uno con otro", es decir, un idéntico y permanente "organismo monádico" o, mejor dicho, un presente intersubjetivo o comunitario de las mónadas, que conserva intencionalmente el pasado monádico general (de todas las mónadas) y donde su futuro es a la vez prefigurado.Y justamente en este proceso se constituye el mundo puesto que en él las mónadas mismas se "realizan" - es decir, son constituidas como mundanas-(Husserl, 2006: p.369).

De lo anterior se desprende que el mundo es para los hombres, es decir, para su inmanencia, "infinito" temporalmente, en indirecta marea generativa, ya que su temporalización avanza a través de las infinitas temporalizaciones que van de mí hacia los otros y a los otros de los otros, y en las cuales se manifiesta siempre como siendo temporalmente. Mas en ello se pone también de manifiesto que el mundo, con toda su temporalidad objetiva en tanto extensiva infinitud, 
no es nada sino para (o "desde") el presente viviente, y por eso es y permanece presente para el copresente de todos nosotros (que se da de acuerdo a la empatía). Así, el tiempo del mundo sólo cobra su sentido como siendo presente en relación con el presente actual del sujeto, pero de un sujeto considerado en tanto originario, presente fluyente en un originario y fluyente ser-unos-con-otros y teniendo o habiendo constituido mundo.Y nosotros, los que somos fluyendo, constituimos uno y el mismo mundo en fluyentes modos de donación, justo como mundo presente fluyente con su pasado fluyente tras de sí, su futuro delante de sí e idéntico en su permanecer a través de esta fluencia (Husserl, 2006: p.58).

Papel del tiempo del mundo en el encuentro de unos con otros

A lo anterior ha de añadirse, sin embargo, que el tiempo objetivo del mundo también aparece como una forma de la coexistencia de las mónadas (entendida en el más amplio sentido), como una forma de su acceso mutuo o de su misma comunidad. Lo anterior se echa de ver con toda claridad, por ejemplo, en el caso de la vida instintiva y el impulso que nos vuelca a los otros de esta manera, en la cual las mónadas se relacionan según la forma de la espaciotemporalidad, conforme a lo próximo y lo lejano, por grados.

Y si bien es cierto que el ser de cada mónada es en-sí y para-sí en una incomenzada (e interminable) autoconstitución en el tiempo inmanente, también lo es que el hecho de su nacimiento (y por otro lado de su muerte) es en la misma inmanencia de la mónada un límite en su autoconstitución temporal-mundana (en cuanto límite en su desarrollo mundano y su ser en el mundo). De manera que con esto último tenemos una particular estructura de la mencionada autoconstitución, que tiene un comienzo y un final; es la constitución de lo mundano en el que la mónada se experimenta como viviendo en un mundo en torno, y en ello llega a ser consciente de otras mónadas y se experimenta en relación con ellas (Husserl, 2006: p.173).

De manera que si las mónadas en cuanto singulares tienen su respectivo ser y temporalidad inmanentes (y lo tienen como aquello 
que precisamente las individualiza), las mónadas en interrelación habrán de tener una temporalidad intermonádica, una forma de su coexistencia, que en el marco de la constitución del mundo como mónadas "realizadas" (esto es, en tanto humanas y "almas" - psiques- en el espacio-tiempo), es el tiempo mundano el cual, en el descubrimiento de la mónada como sujeto trascendental, es índice precisamente del tiempo trascendental que no es sino la forma de la coexistencia subjetiva-trascendental. De ahí que el tiempo trascendental con el ser trascendental coincida con el tiempo del mundo (Husserl, 2006: p.173).

Cada "alma" - ante la mirada trascendental- es la realización de una mónada, siempre conforme al trayecto o duración concreta de su vida. Mas aquí hay que advertir que esta realización no es cosa de esta mónada sola, sino de la totalidad universal de ellas que son, efectivamente, unas para otras en su necesaria relación de dependencia mutua. Las mónadas tienen, pues, una comunitaria y actual experiencia del mundo en el "uno para otro" de la comunicación (por ejemplo en el intercambio de acuerdos). Y en este sentido son directamente acordes cuando tienen un mismo mundo en torno en la comunidad de la percepción. Más aún, ellas tienen una directa comunidad de vida cuando también tienen un mismo pasado recordado y un mismo futuro vital. Las mónadas son, pues, unas para otras en la unidad de un mismo mundo (y así es como se suceden directamente unas tras otras en la unidad de una misma vida comunitaria). La coexistencia de las mónadas, por tanto, sólo es posible en virtud de un mundo constituido que es el mismo para todas (Husserl, 2006: p. 175).

En suma, la constitución trascendental del presente mundano conlleva necesariamente la constitución trascendental de la propia condición mundana (o "realización") de cada sujeto singular trascendental (la mónada concreta) como mundanamente presente ${ }^{20}$. Pero esta última supone la experiencia de lo psíquico ajeno, en particular como

20 Conviene recordar en este punto que, de acuerdo al pensamiento de Husserl, yo, el hombre que reflexiono sobre mí mismo, me encuentro en la reducción trascendental como el (plenamente desarrollado) yo trascendental. El yo trascendental fenomenológico es, pues, un yo del más alto grado, que "tiene pre-dados al yo natural y al fenómeno del mundo". 
experiencia indirecta del co-presente y con ello la coexistencia de todos lo co-humanos en mi presente. Dicha coexistencia mundana funciona, a su vez, como índice que apunta a la coexistencia trascendental de las correspondientes mónadas en un presente trascendental en el que es posible (y sólo en él lo es), la unificación de tal ser "a la vez" unoscon-otros (Husserl, 2006: p.392). E igualmente se indica el pasado del mundo como perteneciente al pasado generativo, como trascendental unidad en la conexión de las generaciones trascendentales, todo ello en el correlativo presente del mundo asimismo co-constituido.

Arribamos, pues, de nueva cuenta, al planteamiento del paralelismo entre la temporalidad trascendental (intersubjetiva) y el tiempo mundano, paralelismo que hinca su raíz en la paradoja que presenta la subjetividad humana al ser a la vez sujeto para el mundo y también, en cierto modo, objeto en el mundo, una parte constitutiva suya ${ }^{21}$. Ahora bien, en el planteamiento que Husserl hizo de este tema en El artículo de la Encyclopaedia Britannica, el filósofo afirmó, como ya sabemos, que la intersubjetividad puramente anímica, tan pronto como se somete a la epojé trascendental, conduce igualmente a su paralela, a la intersubjetividad trascendental. Pero añadió enseguida que dicho paralelismo significa nada menos que equivalencia teórica, ${ }^{22}$ lo que permite trasladar el análisis de un nivel al otro.

21 Para abundar en este tema véase Husserl, 1991: pp.188-196.

22 "Mi yo trascendental es [...] evidentemente 'diferente' del yo natural, pero de ninguna manera como un segundo yo, como un yo separado de él en el sentido natural de la palabra, así como, a la inversa tampoco es un yo unido a él o entrelazado con él en el sentido natural. Es precisamente el campo (concebido en concreción plena) de la experiencia trascendental de sí mismo, que en todo momento puede convertirse, mediante una mera modificación de la actitud, en experiencia psicológica de sí mismo". En la reflexión trascendental se hace visible la objetivación psicológica justamente como objetivación de sí mismo, de manera que "si se ha vuelto comprensible el paralelismo de las esferas de experiencia trascendental y psicológica como una suerte de identidad en la reciprocidad del sentido de ser por virtud de un mero cambio de actitud, entonces también se comprenderá la consecuencia que de allí se sigue y que consiste en el mismo paralelismo y el implícito estar encerradas recíprocamente, de la fenomenología trascendental y la psicología, cuyo tema pleno es la intersubjetividad pura y de doble sentido. En esto sólo hay que tomar en cuenta que la intersubjetividad puramente anímica, tan pronto como se somete a la epojé trascendental, conduce igualmente a su paralela, a la intersubjetividad trascendental. Obviamente, el paralelismo significa nada menos que equivalencia teórica" (Husserl, 1990: pp.74-75). 
En este punto es preciso dedicar una palabra al proceso de formación de la temporalidad propiamente intersubjetiva. Es bien sabido que para Husserl cada "alma” monádica (es decir, cada psiquismo) tiene su propia temporalidad esencial como forma en la que se encierra su respectiva individualidad, y ello ciertamente no se debe a la ubicación de su respectivo cuerpo físico (Körper) en el tiempo objetivo de la naturaleza. Lo anterior debe entenderse, más bien, en el sentido de que en ella se interconectan, ya sea simultánea o sucesivamente, múltiples vivencias o datos anímicos, cada uno de los cuales puede distinguirse a su vez como una unidad individual. Pero lo que ha de subrayarse aquí es que a través de tal entrelazamiento se va forjando, en su particularidad única, su propia historia. De manera que el "tiempo de vida" esencialmente propio de un alma monádica no puede ser confundido o mezclado con el tiempo inmanente propio de otras mónadas, y si bien es cierto que este tiempo (fundamento de la mónada en cuanto tal y por ello "primordial”) puede llegar a ser concorde con el del vecino, ambos somos, cada quien, un yo con una vida propia, una corriente de vivencias, unas determinadas capacidades, disposiciones, etc. (Husserl, 1973: p.338).

La dualidad de los cuerpos vivientes va, entonces, junto con la dualidad de los psiquismos y precisamente a ello subyace la dualidad de las corrientes temporales de vida, esto es, el que no seamos trozos de un solo tiempo ni ciertamente podamos llegar a ser una sola forma en la que los momentos de vida de ambos fueran indistintamente cumplidos o realizados.

Pero, ¿acaso no es verdad que las almas coexisten sólo a través de su unión con los cuerpos y, por ende, a través del tiempo universal de la naturaleza? Sin duda, cada cuerpo tiene su propia duración objetiva como un momento de la duración natural general, pero ello ocurre precisamente por cuanto se halla inserto en la red de relaciones causales que comprende el todo de la naturaleza. Sin embargo ¿puede reducirse a esto la conexión de todas las almas? $\mathrm{Si}$ cada alma considerada en sí y para sí misma tiene su tiempo propio 
como unidad de vida ${ }^{23}$, un tiempo universal como forma de concreción para la totalidad de las almas (es decir, un tiempo inter o supra-monádico) tendría que ser un tiempo de un orden más alto, como una forma fundada. Para dicha forma serían las mónadas singulares, así como sus respectivos tiempos vitales singulares, "contenidos temporales", los cuales, en la medida en que coinciden y por lo mismo coexisten, pueden ser comprendidos en el sentido de un tiempo intermonádico universal (Husserl, 1973: p.340).

Se trata, entonces, de un tiempo que es de un orden sintético más alto que aquél que corresponde a la síntesis continuamente efectuada de una vida individual, y que, en cambio, se sigue de la coincidencia intencional de las almas que se corresponden en el ser "uno para el otro" (Husserl, 1973: p.334). Con ello tenemos, en efecto, la formación de una comunidad de sujetos yo, temporalmente coexistentes en su ser viviente, pero ahora considerados en una conexión y una forma de coexistencia fundada en las almas mismas consideradas en cuanto tales. Pues las almas son sujetos yo humanos en la concreción de sus fluyentes vidas psíquicas; pero ellas no son solamente en sí y para sí, esto es, en su temporalidad monádica, sino que son también, y lo son esencialmente, en comunidad actual o potencial con otras (Husserl, 2006: pp.342 y 334).

Trasladémonos ahora al ámbito propiamente trascendental. Encontramos aquí que al efectuar un acto de empatía y con ello tener al otro como copresente, tengo también su presente vivo como anunciándose en mí apresentativamente, a la vez que lo anuncia a él como teniéndome a mí en su presente viviente constituido a la manera del co-presente, dado que él mismo es apresentado en mí y yo en él. Y al coincidir mis proto-impresiones originarias del ahora

23 Husserl advierte en este punto, sin embargo, que la constitución monádica es esencialmente tal que ella implica la naturalización de cada mónada y con ello la temporalización de la misma en la espacio-temporalidad del mundo. Con lo cual el tiempo inmanente toma el sentido de un proceso en dicho tiempo objetivo o cósmico (Husserl, 1973: p.639). Con todo, lo anterior no debe hacernos perder de vista que, a fin de cuentas, el tiempo mundano sólo tiene sentido como existente (es decir, como presente), en relación al presenciar actual de los sujetos, mismos que son precisamente presente originariamente fluyente, en el ser-con-otro asimismo originariamente fluyente y que, en tanto comunidad, constitutivamente tienen el mundo. 
con las del otro, el punto-fuente absoluto del que brota toda modalidad temporal es en esta concordancia el mismo para ambos respecto de su forma y contenido, por lo que concuerdan también, siempre en forma y contenido, las inmediatas modificaciones fluyentes de lo recientemente sucedido que se va hundiendo cada vez más en el pasado, etc., de modo que con ello se constituye un temporal "a la vez" de lo sobremonádico o un tiempo intermonádico de orden superior que nos abraza a ambos (Husserl, 1973: p.343).

Ocurre entonces que la misma experiencia tiene una duración temporal que aparece como "externa", es decir, en tanto "presente objetivo" que se mantiene en coincidencia con mi aparición duradera y con la que se une y coincide también, punto por punto, la aparición duradera del otro e incluso de todo otro que participe de este mismo y unitario "ahora" objetivo/intersubjetivo. Sin embargo, hay que aclarar de inmediato que este "a la vez" de una coincidencia entre mi presente originario y el ajeno, del que arriba se dijo que puede decirse en cierto modo un ahora "objetivo" no se confunde simplemente con el tiempo cósmico, sino que (desde el plano trascendental abierto por la reducción) se trata más bien de un "tiempo general" (Allzeit) o "tiempo de todos" (Husserl, 1973: p.332), ${ }^{24}$ es decir, de una suerte de tiempo trascendental de todos frente a los tiempos trascendentales propios de las mónadas singulares. Y como de lo que se trata aquí es del punto-fuente para la constitución de un pasado y un futuro fluyentes, lo que se constituye en esta corriente cobrará entonces la forma objetiva (es decir, reconocible como idénticamente la misma por cualquier sujeto) del tiempo objetivo fijo - de todas las "almas" (Husserl, 1973: p.334).

En la formación de la comunidad de las mónadas en la temporalidad inter-monádica aparece, pues, una nueva unidad, aquella de la coexistencia que temporalizando crea un tiempo al que pertenecen, por mediatamente que nos parezca, todos los tiempos inmanentes, todas las corrientes de vivencias y sus yo-polos centrantes, no como

24 Aunque también es cierto que dicho tiempo "objetivo"/intersubjetivo, aunque no se asimila sin más a éste (puesto que le da sentido, es decir, lo constituye), "concuerda sin embargo con el tiempo de la naturaleza". 
partes propiamente dichas de este tiempo sino como parcialmente simultáneas, parcialmente sucesivas, además de los procesos monádico-temporales que se superponen o son disyuntivos y que, desde luego, también habrá que tomar en cuenta (Husserl, 1973: p.636).

En la síntesis de coexistencia monádica nos tenemos, en suma, a todos nosotros (los sujetos-yo monádicos) en la comunidad del ser y ello en la mutua exterioridad temporal, si bien en un temporalizante llegar a ser "unos en otros". Allí se halla también una temporalización de las originariedades que son, cada una, necesariamente temporalizantes o bien una comunitarización interna de las mismas - y a la vez, aunque en segunda línea, una síntesis que constituye la universalidad de la naturaleza (y mundo) para todos-(Husserl, 1973: p.668).

El tiempo trascendental intermonádico y el tiempo objetivo (mundano), paralelos y en ello necesariamente concordantes, pueden decirse, a la postre, "un mismo orden de tiempo". Lo anterior se justifica por cuanto cada yo empírico se revela "portador de un yo trascendental". No porque este último fuera una mera parte suya, sino que se trata de exactamente él mismo, en la medida en que se halla a sí propio necesariamente en el mundo y en ello se descubre también como dador de tal sentido ${ }^{25}$. Y como la base desde donde habrá de cobrar sentido toda relación intersubjetiva la ofrece, para cada quien, la temporalización de su propio tiempo inmanente, la formación de la temporalidad intermonádica no podrá deberse sino a una constante temporalización de temporalizaciones, que en cierto modo deberá suponer (como pre-dada) una comunidad de sujetos encarnados que se abren al mundo, viven y se encuentran mutuamente en él.

Sin llegar explícitamente hasta ella, el pensamiento husserliano avanza así, significativamente, hacia el reconocimiento de una conciencia encarnada como lo que soporta el mencionado manejo en paralelas y ¿por qué no decirlo? en última instancia está llamado también a superarlo.

25 'Todo hombre 'porta en sí un yo trascendental', pero no como parte real o como estrato de su alma (lo cual sería un sinsentido), sino en la medida en que él es la autoobjetivación del yo transcendental concernido, autoobjetivación mostrable mediante la autorreflexión fenomenológica. Pero todo hombre que realiza la epojé podría, ciertamente, reconocer su último yo, que actúa en todo su hacer humano" (Husserl, 1991: p.196). 


\section{REFERENCIAS}

Husserl, Edmund. 1973. Zur Phänomenologie der Intersubjektivität. Dritter Teil: 1929-1935. (Husserliana XV). Herausgegeben von Iso Kern. Den Haag: Martinus Nijhoff.

HuSSERL, Edmund. 1980. Experiencia y juicio. Investigaciones acerca de la genealogía de la lógica. México, UNAM, Instituto de Investigaciones Filosóficas. Redacción y edición de Ludwig Landgrebe. Traducción de Jas Reuter.

Husserl, Edmund. 1990. El artículo de la Encyclopaedia Britannica. México, UNAM, Instituto de Investigaciones Filosóficas. Traducción y edición de Antonio Zirión Q.

HuSSERL, Edmund. 1991. La crisis de las ciencias europeas y la fenomenología transcendental. Barcelona, Crítica. Traducción de Jacobo Muñoz y Salvador Mas.

Husserl, Edmund. 1994. Problemas fundamentales de la fenomenología. Madrid, Alianza Editorial. Traducción de César Moreno y Javier San Martín.

Husserl, Edmund. 1996. Meditaciones cartesianas ( $2^{\mathrm{a}}$ ed.). México, Fondo de Cultura Económica. Traducción de José Gaos y Miguel García-Baró.

HuSSERL, Edmund. 1997a. Ideas relativas a una fenomenología pura y una filosofía fenomenológica. Libro segundo: Investigaciones fenomenológicas sobre la constitución. Trad. Antonio Zirión Quijano. México: UNAM, Instituto de Investigaciones Filosóficas.

Husserl, Edmund. 1997b. "Teleología” en Daimon. Revista de Filosofía (Universidad de Murcia. Departamento de Filosofía y Lógica), n 14, pp. 5-14. Traducción de Agustín Serrano de Haro del texto numerado como el 22 en el vol. XV de Husserliana.

Husserl, Edmund. 1998. De la synthèse passive (Husserliana XI). Paris: Presses Universitaires de France. Traduction française par J. Million.

Husserl, Edmund. 2001. Die Bernauer Manuskripte über das Zeitbewusstsein (1917/18). (Husserliana XXXIII). Dordrecht, The Netherlands: Kluwer Academic Publishers. Herausgegeben von Rudolf Bernet und Dieter Lohmar.

Husserl, Edmund. 2002. Lecciones de fenomenología de la conciencia interna del tiempo. Madrid, Editorial Trotta. Traducción de Agustín Serrano de Haro.

Husserl, Edmund. 2006. Späte Texte über Zeitkonstitution (1929-1934). Die C-Manuskripte. Husserliana Materialen. Band VIII. Springer, Dordrecht, The Netherlands. Herausgegeben von Dieter Lohmar.

Montavont, Anne. 1999. De la passivité dans la phénoménologie de Husserl. Paris, Presses Universitaires de France (Épiméthée).

Walton, Roberto. 1984. "Génesis y anticipación en el horizonte temporal” en Escritos de Filosofía (Buenos Aires), no 7, pp. 35-52.

ZAHAVI, Dan. 1998. "Self-awareness and affection”, en Natalie Depraz and Dan Zahavi (eds.) Alterity and facticity. New perspectives on Husserl. Dordrecht/Boston/London, Kluwer Academic Publishers, pp. 205-228. 